\title{
Pediatric COVID: How is it Different From Adults?
}

\author{
Rakhee Goyal, Rohan Sharma \\ Department of Anesthesia and Intensive Care, Madhukar Rainbow Children's Hospital, New Delhi, India
}

\section{Abstract}

COVID 19 pandemic has affected the world for more than one year now. It has had impact on children as well, but the numbers have been fewer than adults, with lesser morbidity. Children have been commonly asymptomatic and are suspected to be the spreaders to the more susceptible part of the community. Nasopharyngeal swab testing is difficult and challenging in smaller children, and therefore their results should be interpreted with caution. Multisystem involvement has been seen in some children who required ICU admission. Most centers treated these cases as a multisystem inflammatory syndrome and used vasoactive agents for support. Overall, children showed lower morbidity and mortality all over the world.

Keywords: COVID-19, multisystem inflammatory syndrome, pediatric, spreaders

\section{INTRODUCTION}

At the start of December 2019, the city of Wuhan in China had an outbreak of pneumonia among its citizens. The number of cases of this pneumonia continued to rise at an alarming rate and the causative organism could not be identified. In January 2020, a zoonotic virus was found as the causal organism and was named Severe Acute Respiratory Syndrome Coronavirus 2 (SARS-CoV-2). The spread of this virus occurred via aerosols and droplets with a very high secondary infectivity rate and has become a global health problem. The coronavirus disease was declared as a pandemic on March 11, 2020. 213 countries and territories have reported a total number of 114 million confirmed cases of COVID-19 and a death toll of 2.52 million as of February 28, 2021. India has witnessed over 11.1 million confirmed cases and more than 157,000 deaths of the novel coronavirus disease (COVID-19), with the numbers increasing with every passing day. ${ }^{[1]}$

Globally, fewer cases of COVID-19 have been reported in children as compared to adults. For instance, in the United States, children ( $0-17$ years) comprise $22 \%$ of the total population, and only $13.1 \%$ of cases were children. Although no specific registry exists, the same can be said about our country as well, as the hospitalization of pediatric COVID-19 has been few and far between. All around the world, no specific census exists for pediatric COVID-19 patients. In the United States, as per the available reported data till August

\begin{tabular}{|l|l|}
\hline \multicolumn{3}{|c|}{ Access this article online } \\
\hline Quick Response Code: & Website: \\
\hline & www.ijrc.in \\
\hline & \\
\hline
\end{tabular}

27,2020 , children were $0 \%-0.25 \%$ of all COVID- 19 deaths, and the mortality rate was $0 \%-0.04 \%$ among all pediatric COVID-19 cases. ${ }^{[2]}$

Mainly, three types of tests are available for the detection of SARS-CoV-2 infection: molecular tests (reverse transcription polymerase chain reaction [RT-PCR]), antigen tests (rapid test), and antibody test, the gold standard being the RT-PCR. The RT-PCR and antigen tests require a nasopharyngeal swab that needs trained personnel to collect the sample. The sampling process causes discomfort or pain to the child, often leading to crying, compounded almost always by stranger anxiety, and therefore, the sample collection can be very challenging as well as unreliable in children, as compared to adults. A negative RT-PCR report should therefore be considered with caution in children.

The rapid test should not be used for routine clinical care and can be best reserved for population surveillance studies. The interpretation of the third type of test, antibody test, is less straightforward. The presence or absence of antibodies should not be used to group people in classrooms at the current time.

Address for correspondence: Dr. Rakhee Goyal, Department of Anesthesia and Intensive Care, Madhukar Rainbow Children's Hospital, New Delhi - 110 017, India. E-mail: rakheegoyalkumar@gmail.com

This is an open access journal, and articles are distributed under the terms of the Creative Commons Attribution-NonCommercial-ShareAlike 4.0 License, which allows others to remix, tweak, and build upon the work non-commercially, as long as appropriate credit is given and the new creations are licensed under the identical terms.

For reprints contact: WKHLRPMedknow_reprints@wolterskluwer.com

How to cite this article: Goyal R, Sharma R. Pediatric COVID: How is it different from adults? Indian J Respir Care 2021;10:S55-9.

Received: 21-01-2021 Accepted: 10-03-2021

Revised: 10-03-2021 Published: 29-04-2021 
Research and development continue on various new types of tests, and doctors are advised to remain up to date with the current literature. ${ }^{[3]}$

In most hospitals across the country, all inpatient children are tested using RT-PCR at the time of admission for elective surgeries or admission in the intensive care unit (ICU), the report being considered valid up to $72 \mathrm{~h}$ (minimum time for the patient to become infective if the infection is acquired after giving the sample for testing). For emergency cases, patients are first admitted to an isolation ward until the report for RT-PCR is available and all patients with a negative report are then shifted out from the isolation ward to the pediatric ward. The rapid antigen tests are also used in many institutions as a quick screening tool, so that the patients are suitably segregated. To reduce the viral load, routine chlorhexidine mouth wash is also suggested for the inpatients. ${ }^{[4]}$

Evidence suggests that children have a higher nasopharyngeal viral load and can transmit the virus much more effectively as compared to adults. ${ }^{[5]}$ SARS-CoV-2 can remain viable on various surfaces for hours to days, but the transmission has been more commonly observed through aerosols than through fomites. ${ }^{[6]}$ Furthermore, fecal shedding has been observed for several weeks after diagnosis, which raises concerns regarding feco-oral transmission of virus, but has not been substantially evidenced yet. ${ }^{[7]}$ The low infection rate in children can be because they were confined to their homes with all the schools being closed and are only interacting with their close family members.

Tackling the spread of coronavirus will be a challenge at the school level, especially the small children. Teaching toddlers about the usage of mask throughout a long school day is difficult in itself. Furthermore, explaining and ensuring precautions such as hand hygiene and maintaining social distancing among children in a classroom will demand additional resources from the already stretched schools. This problem will multiply many-fold in a low-income country such as ours. As already discussed, the number of children that are asymptomatic constitute a large fraction of those infected. These children can then become superspreaders and spread the virus throughout the school, which will eventually be carried to their respective homes, infecting a huge proportion of the society at large. Recently, on March 1, 2021, 54 students of one school in the Karnal district of Haryana were found positive and the school had to be converted into a containment zone. ${ }^{[8]}$ A similar story had unfolded in Malappuram district of Kerala, where 190 students and 70 teachers were found to be positive in two government schools, one month after the schools were opened for class $10^{\text {th }}$ and $12^{\text {th }} \cdot{ }^{[9]}$

The incubation period of COVID-19 is the same in children as in adults at 2-12 days with a median of 6 days. The signs and symptoms of COVID-19 vary widely among the pediatric population and this creates a challenge to identify the infected individuals using a symptom-based testing approach. A recent systematic review has reported the asymptomatic individuals to comprise $16 \%$ of total pediatric cases, while other evidence reports $45 \%$ of pediatric patients to be asymptomatic. The most common symptoms for children were fever $(70 \%)$, cough $(39 \%)$, nausea/vomiting (32\%), and dyspnea (30\%). While upper respiratory tract infections are characteristic of COVID-19, some patients presented with nonspecific symptoms such as fatigue, loss of smell, abdominal pain, and decreased appetite. ${ }^{[10,11]}$

Children infected with COVID-19 have also been reported to develop a multisystem inflammatory syndrome in children (MSI-C), also known as pediatric inflammatory multisystem syndrome temporarily associated with SARS-CoV2 (PIMS-TS), which appears both distinct and similar to Kawasaki disease or toxic shock syndrome. ${ }^{[12-15]}$ MSI-C can lead to shock and organ failure requiring intensive care admission. The pathophysiology of MSI-C is still unknown and possibly includes the antibody-mediated recognition of self-antigens (viral mimicry) or T-cell-mediated recognition of infected cells or an immune complex formation. Most cases of MSI-C were managed by following the standard protocols for Kawasaki disease with vasoactive agents or inotropic support, required in patients suffering from hypotension. The safety and efficacy of these treatments is yet to be proven. The medium-to-long-term sequelae of MSI-C remain unknown and close follow-up may be required.

Meanwhile, the WHO has released a preliminary case definition that includes fever and elevated inflammatory markers for more than 3 days with two of the following features: (A) rash or bilateral nonpurulent conjunctivitis or mucocutaneous inflammation signs (oral, hands, or feet); (B) hypotension or shock; (C) features of myocardial dysfunction, pericarditis, valvulitis, or coronary abnormalities (including echocardiogram findings or elevated troponin or N-terminal pro B-type natriuretic peptide); (D) evidence of coagulopathy (elevated prothrombin time, partial thromboplastin time, and elevated D-dimers); and (E) acute gastrointestinal problems (diarrhea, vomiting, or abdominal pain). ${ }^{[16]}$

The Royal College for Pediatric and Child Health (RCPCH) defines PIMS-TS as fever and elevated inflammatory markers with single or multiple organ dysfunction (shock, respiratory, renal, gastrointestinal, or neurological disorder). ${ }^{[17]}$ Both the WHO and the RCPCH exclude cases that have any proven microbial cause, including bacterial sepsis or streptococcal and staphylococcal shock syndromes. In a series of cases from London that presented with multi-inflammatory syndrome, children had varying symptoms such as fever, rash, conjunctivitis, and gastrointestinal problems. Eight of these children required respiratory assistance with one needing oxygen support, two requiring noninvasive ventilation, four requiring intubation and mechanical 
ventilation, and one needing ECMO. All the sick 8 patients required vasopressor support, and 5 patients demonstrated ventricular dysfunction on cardiac imaging. ${ }^{[14]}$ It should be noted that all such symptoms may not even be present, and hence, a high index of suspicion is required to detect the SARS-CoV-2 in children. The best way to help prevent a child from getting MSI-C is to take precautions to prevent the exposure to COVID-19 virus.

Laboratory studies among children are also known to be nonspecific. An increase is usually seen in the inflammatory markers such as C-reactive protein, procalcitonin, erythrocyte sedimentation rate, D-dimer, and interleukin-6. On performing complete blood counts, total leukocyte count was within the normal range, most frequently with observed neutropenia (44.4\%) and lymphocytosis $(39.9 \%) .{ }^{[18]}$ Liver and muscle enzymes as well as lactate dehydrogenase, myoglobin, and creatinine kinase are also shown to have an upward trend.

For chest X-ray and computed tomography (CT) scans, 23.6\% and $18.9 \%$ of patients with diagnosed COVID pneumonia had normal scans, respectively. Patchy lesions on X-Ray and ground-glass opacities on CT scans were the most frequent abnormality. ${ }^{[19,20]}$

Another concern was the vertical transmission of coronavirus from an infected mother to her baby. Some initial reports did support the idea of a vertical transmission as neonates of infected mothers were found to have the infection; ${ }^{[21]}$ recent reports refute such an observation. In the study by Chen et al., 9 neonates born to infected mothers with COVID-19, delivered by cesarean section, were not found to be infected. ${ }^{[22]}$ Similarly, Zhang et al. found that all 10 neonates of infected mothers tested negative for the coronavirus. ${ }^{[23]}$ The samples of breast milk and placenta were also negative for the SARS-CoV-2 when determined by RT-PCR, and vertical transmission was not observed with either SARS-CoV-1 or in MERS-CoV. ${ }^{[24]}$ Therefore, it can be said that the vertical transmission of COVID-19 is unlikely, or at best, extremely rare.

The effect of SARS-CoV-2 on the developing fetus, its organ development, growth abnormalities, or the incidence of spontaneous abortions and premature labor cannot be commented upon due to limited amount of evidence available as of now. ${ }^{[25,26]}$

Pediatric anesthesiologists are involved in the perioperative care of the pediatric patients. They are expected to handle these cases safely and effectively. ${ }^{[27-29]}$ First, those involved in the care of COVID-positive patients must wear appropriate personnel protective equipment and appropriate N95 masks. Preanesthetic checkup clinics should be done with caution, and the preoperative evaluations could be done virtually. Many precautions should be in place during induction of a positive patient. Intubation and extubation are considered as aerosol-generating procedures, whether in the OT or in the ICU. The time from start of induction to intubation should be minimized to reduce the risk of virus shedding. The number of personnel should be minimal during this time period also. Preoxygenation should be performed with a tight-fitting face mask and the assembly can be covered by a transparent sheet to minimize the spread of secretions to the air ${ }^{[30]}$ Sedation, such as intranasal midazolam or oral ketamine, can be used for combative or uncooperative children. The use of video laryngoscope should be preferred over direct laryngoscope and cuffed tubes preferred over uncuffed ones, with laryngoscopy done after ensuring adequate relaxation to avoid coughing at the time of intubation. Intraoperatively, fresh gas flows should be kept to a minimum, with monitoring for any loss of respiratory gas volume. At extubation, there should be minimal personnel around, and those present should have adequate protective gear. Antiemetics must be used to decrease retching and vomiting. Deep extubation should be considered wherever possible to avoid coughing. The assigned anesthesiologist should decide the time of discharge from the operation theater. All the airway equipment should be sterilized as per the hospital infection control policies. The carbon dioxide absorber should be replaced after every positive case as it provides a large surface area for the exhaled viral particles to stick. The surface of the anesthesia machine should be disinfected properly.

Treatment for COVID-19 for children consists of supportive care, including oxygen therapy as indicated. As of today, no single drug or biologics have been approved by the FDA for treatment or the prevention of SARS-CoV-2. Numerous antivirals, immunomodulators, vaccines, and plasma therapy are at present undergoing trials for the treatment of pediatric coronavirus disease. The decision to treat pediatric patients with these drugs should be made on a case-by-case basis, and it involves discussion with a multidisciplinary pediatric team including intensivists, cardiologists, and infectious disease specialists among others.

The RCPCH has produced treatment guidelines. Corticosteroids should be considered for children $>5$ years of age with critical COVID-19; the dosing should be 150 $\mathrm{mg} / \mathrm{kg}$ once daily for 10 days. They can also be considered for children between 44 weeks of gestational age and 5 years on a case-by-case basis. Remdesivir should be considered for children $>40 \mathrm{~kg}$ and $>12$ years with COVID-19 requiring supplemental oxygen. The Royal College also recommends investigational treatment, but only within a treatment trial. Antiviral treatments are likely to benefit the most during the first phase of illness, while immunomodulatory treatment may be indicated if there is evidence of hyperinflammation in the second phase of illness. The treatment options include synthetic neutralizing antibodies, tocilizumab, anakinra, and baricitinib.

Respiratory support is an integral component of management of sick children. Most children, even those with lung involvement, 
Goyal and Sharma: Pediatric COVID

seldom require respiratory support. Children should receive oxygen by low-flow nasal canula (LFNC) in case they develop hypoxia, rather than high-flow nasal canula (HFNC). If children are hypoxic despite LFNC, HFNC can be tried. Further treatment by intubation and mechanical ventilation should be used as a last resort treatment modality.

There are many limitations to writing on the coronavirus. First, most of the articles available at present are case reports or cases with very few numbers. Second, the level of evidence from various studies is still very low. Suspected cases that have not been tested positive were not included in many studies. Different forms of tests with varying sensitivity and specificity are available. While earlier the cases were confirmed by RT-PCR tests, where the swab from the nasopharynx or the oropharynx was taken with various amounts of success, recently, rapid antigen test is being used in increasing number in India that has very low specificity. Then, very few studies divide the symptom/ laboratory parameters into adults versus children and hence a comparative review will actually take some time to be available. Finally, the data on COVID-19 are very dynamic and changing even as we write this article.

In nutshell, this pandemic has shown lesser incidence, morbidity, and mortality in children. Children should not be ignored in this whole scenario as they can be the asymptomatic spreaders in the community. The decision of reopening of schools has been challenging for the governments, and that is why in most places, the children are still studying from home. The UN has recently released the estimated degree of impact this pandemic has had on the education of a large number of children who could not get access to education in any substantial form. ${ }^{[31]}$

Among those children who require hospital admission, the multisystem involvement is worrying and unpredictable. Hence, due diligence is advocated in looking at every child in the community during this pandemic.

\section{Financial support and sponsorship}

Nil.

\section{Conflicts of interest}

There are no conflicts of interest.

\section{RefERENCES}

1. World Health Organisation. Countries Where COVID-19 Has Spread. Available from: https://www.worldometers.info/coronavirus/countrieswhere-coronavirus-has-spread. [Last accessed on 2021 Mar 01].

2. American Academy of Pediatrics. Children and COVID-19: State Level Data Report. Available from: https://services.aap.org/en/pages/2019novel-coronavirus-covid-19-infections/children-and-covid-19-statelevel-data-report. [Last accessed on $2021 \mathrm{Feb} 25$ ].

3. Centers for Disease Control and Prevention. Available from: https:// www.cdc.gov/coronavirus/2019-ncov/symptoms-testing/testing. html. [Last accessedon $2021 \mathrm{Feb} 25]$.

4. Kapoor MC. Reducing the viral load while securing the airway. J Anaesthesiol Clin Pharmacol 2020;36:S147-8.

5. Heald-Sargent T, Muller WJ, Zheng X, Rippe J, Patel AB, Kociolek LK.
Age-related differences in nasopharyngeal severe acute respiratory syndrome coronavirus 2 (SARS-CoV-2) levels in patients with mild to moderate coronavirus disease 2019 (COVID-19). JAMA Pediatr 2020;174:902-3.

6. Chen J. Pathogenicity and transmissibility of 2019-nCoV - A quick overview and comparison with other emerging viruses. Microbes Infect 2020;22:69-71.

7. Gu J, Han B, Wang J. COVID-19: Gastrointestinal manifestations and potential fecal-oral transmission. Gastroenterology 2020;158:1518-9.

8. Hindustan Times. 54 Students Test COVID-19 Positive at School in Haryana's Karnal. Available from: https://www.hindustantimes.com/ india-news/54-students-test-covid-19-positive-at-school-in-haryana-skarnal-101614687017066.html. [Last accessed on 2021 Mar 05].

9. The Hindu. In Kerala, 150 Students of a School Test Positive. Available from: https://www.thehindu.com/news/national/kerala/150-students-ofa-school-test-positive. [Last accessed on 2021 Mar 05].

10. Foster CE, Moulton EA, Munoz FM, Hulten KG, Versalovic J, Dunn J, et al. Coronavirus Disease 2019 in children cared for at texas children's hospital: Initial clinical characteristics and outcomes. J Pediatric Infect Dis Soc 2020;9:373-7.

11. Shekerdemian LS, Mahmood NR, Wolfe KK, Riggs BJ, Ross CE, McKiernan CA, et al. Characteristics and outcomes of children with Coronavirus Disease 2019 (COVID-19) infection admitted to US and Canadian pediatric intensive care units. JAMA Pediatr 2020;174:868-73.

12. Feldstein LR, Rose EB, Horwitz SM, Collins JP, Newhams MM, Son MB, et al. Multisystem inflammatory syndrome in U.S. children and adolescents. N Engl J Med 2020;383:334-46.

13. Jones VG, Mills M, Suarez D, Hogan CA, Yeh D, Segal JB, et al. COVID-19 and Kawasaki disease: Novel virus and novel case. Hosp Pediatr 2020;10:537-40.

14. Riphagen S, Gomez X, Gonzalez-Martinez C, Wilkinson N, Theocharis P. Hyperinflammatory shock in children during COVID-19 pandemic. Lancet 2020;395:1607-8.

15. Verdoni L, Mazza A, Gervasoni A, Martelli L, Ruggeri M, Ciuffreda M, et al. An outbreak of severe Kawasaki-like disease at the Italian epicentre of the SARS-CoV-2 epidemic: An observational cohort study. Lancet 2020;395:1771-8.

16. WHO. Multisystem Inflammatory Syndrome in Children and Adolescents with COVID-19. Available from: https://www.who.int/ publications/i/item/multisystem-inflammatory-syndrome-in-childrenand-adolescents-with-covid-19. [Last accessed on 2020 Sep 10].

17. The Royal College of Paediatrics and Child Health. Guidance-Paediatric Multisystem Inflammatory Syndrome Temporally Associated with COVID-19 (PIMS); 2020. Available from: https://www.rcpch.ac.uk/ resources/guidance-paediatric-multisystem-inflammatory-syndrometemporally-associated-covid-19-pims. [Last accessed on 2021 Feb 25].

18. Qiu H, Wu J, Hong L, Luo Y, Song Q, Chen D. Clinical and epidemiological features of 36 children with coronavirus disease 2019 (COVID-19) in Zhejiang, China: An observational cohort study. Lancet Infect Dis 2020;20:689-96.

19. Chan JF, Yuan S, Kok KH, To KK, Chu H, Yang J, et al. A familial cluster of pneumonia associated with the 2019 novel coronavirus indicating person-to-person transmission: A study of a family cluster. Lancet 2020;395:514-23.

20. Huang C, Wang Y, Li X, Ren L, Zhao J, Hu Y, et al. Clinical features of patients infected with 2019 novel coronavirus in Wuhan, China. Lancet 2020;395:497-506.

21. Dong L, Tian J, He S, Zhu C, Wang J, Liu C, et al. Possible vertical transmission of SARS-CoV-2 from an infected mother to her newborn. JAMA 2020;323:1846-8.

22. Chen H, Guo J, Wang C, Luo F, Yu X, Zhang W, et al. Clinical characteristics and intrauterine vertical transmission potential of COVID-19 infection in nine pregnant women: A retrospective review of medical records. Lancet 2020;395:809-15.

23. Zhang L, Jiang Y, Wei M, Cheng BH, Zhou XC, Li J, et al. Analysis of the pregnancy outcomes in pregnant women with COVID-19 in Hubei Province. Zhonghua Fu Chan Ke Za Zhi 2020;55:166-71.

24. Chen S, Huang B, Luo DJ, Li X, Yang F, Zhao Y, et al. Pregnancy with new coronavirus infection: clinical characteristics and placental pathological analysis of three cases. Zhonghua Bing Li Xue Za Zhi 
Goyal and Sharma: Pediatric COVID

2020;49:418-23.

25. Rasmussen SA, Smulian JC, Lednicky JA, Wen TS, Jamieson DJ. Coronavirus Disease 2019 (COVID-19) and pregnancy: What obstetricians need to know. Am J Obstet Gynecol 2020;222:415-26.

26. Mimouni F, Lakshminrusimha S, Pearlman SA, Raju T, Gallagher PG, Mendlovic J. Perinatal aspects on the covid-19 pandemic: A practical resource for perinatal-neonatal specialists. J Perinatol 2020;40:820-6.

27. Peng PW, Wong DT, Bevan D, Gardam M. Infection control and anesthesia: Lessons learned from the Toronto SARS outbreak. Can J Anaesth 2003;50:989-97.
28. Scales DC, Green K, Chan AK, Poutanen SM, Foster D, Nowak K, et al. Illness in intensive care staff after brief exposure to severe acute respiratory syndrome. Emerg Infect Dis 2003;9:1205-10.

29. Loeb M, McGeer A, Henry B, Ofner M, Rose D, Hlywka T, et al. SARS among critical care nurses, Toronto. Emerg Infect Dis 2004;10:251-5.

30. Kamming D, Gardam M, Chung FI. Anaesthesia and SARS. Br J Anaesth 2003;90:715-8.

31. UNICEF. Available from: https://data.unicef.org/resources/remotelearning-reachability-factsheet. [Last accessed on 2021 Mar 05]. 